\title{
ANALISIS EFISIENSI KREDIT MODAL VENTURA UNTUK NELAYAN PERIKANAN TANGKAP (Studi Kasus Nelayan di Kabupaten Tegal)
}

\author{
Benny Osta Nababan ${ }^{1}$ dan Yesi Dewita Sari ${ }^{2}$ \\ ${ }^{1}$ Staf Pengajar di Departemen Ekonomi Sumberdaya dan Lingkungan pada Institut Pertanian Bogor. \\ ${ }^{2}$ Peneliti pada Balai Besar Riset Sosial Ekonomi Kelautan dan Perikanan \\ JI. KS. Tubun Petamburan VI, Jakarta 10260 \\ Telp. 021 53650162/Fax. 02153650159 \\ Diterima 18 Agustus 2009 - Disetujui 28 Desember 2009
}

\begin{abstract}
ABSTRAK
Penelitian ini bertujuan untuk mengetahui efisiensi relatif pemberian kredit modal ventura terhadap nelayan di Kabupaten Tegal yang melakukan penangkapan menggunakan alat tangkap cantrang. Data yang digunakan terdiri dari data primer dan sekunder. Data Envelopment Analysis (DEA) digunakan untuk mengetahui efisiensi relatif nelayan penerima kredit ventura dibandingkan nelayan bukan penerima. Analisis juga dikembangkan dengan menggunakan 2 skenario yaitu maksimisasi output dan minimisasi biaya. Hasil penelitian menunjukkan bahwa dengan menggunakan seluruh variabel input dan output, maka 6 dari 7 nelayan penerima kredit ventura efisien $100 \%$ dan hanya 2 nelayan responden tidak menerima kredit ventura yang memiliki efisiensi 100\%. Berdasarkan skenario 1 dan 2, hanya 2 nelayan penerima kredit ventura yang mengalami efisiensi $100 \%$; sedangkan yang lainnya berkisar antara $70 \%-100 \%$. Nelayan tidak menerima kredit ventura memiliki efisiensi $<70 \%$. Pemberian kredit modal ventura dapat meningkatkan efisensi usaha perikanan tangkap terutama bagi nelayan yang melakukan penangkapan jauh dari pantai.
\end{abstract}

Kata kunci : modal ventura, efisiensi, nelayan

\section{Abstract : Efficiency analysis of Ventura Capital Credit for Fisher's Household (Case Study of Fishers in Tegal District). By: Benny Osta Nababan and Yesi Dewita Sari.}

This research aimed to understand relative efficiency of the ventura credits to Tegal district's fishers whose cantrang fishing unit. This research used primary and secondary data and applied Data Envelopment Analysis (DEA) to find out relative efficiency of fisher who receive the ventura credit, and compare it with the fishermen without ventura credit. By using two scenarios of maximization output and minimization input, this research results show that using all output and input variables, six of seven fishers received ventura credit have a relative efficiency of $100 \%$ and only 2 fishers not received the ventura credit have relative efficiency $100 \%$. Based on first and second scenarios, 2 fishers received ventura credit have a relative efficiency of $100 \%$ and others have a relative efficiency ranging from $70 \%$ to $100 \%$. Fishers who are not received ventura credit have a relative efficiency less than $70 \%$. Ventura credit enables to increase relative efficiency of fishers, especially for those who fishing beyond coastal area.

Keywords: ventura capital, efficiency, fishers 


\section{PENDAHULUAN}

Saat ini Indonesia memang sedang berupaya mengembangkan sektor kelautan dan perikanan, namun kendala yang dirasakan cukup mengganggu upaya pertumbuhan usaha ini adalah masalah ketersediaan modal dan infrastruktur. Harus diakui, kurangnya perhatian pemerintah pada waktu yang lalu pada sektor kelautan dan perikanan ini berdampak pada ketertinggalan sektor ini dibanding sektor yang lainnya. Salah satu pihak yang paling merasakan ketertinggalan sektor ini adalah nelayan. Hambatan utama yang paling dirasakan nelayan sebagai pelaku terdepan usaha kelautan dan perikanan adalah kendala pendanaan. Rata-rata nelayan mengeluhkan sulit memperoleh dukungan pendanaan, khususnya dari perbankan karena masih banyaknya kendala teknis yang dihadapi nelayan. Perbankan di lain pihak juga merasakan kesulitan tersendiri pada saat akan memberikan kredit kepada para nelayan ini karena secara teknis perbankan akan mensyaratkan penerima kredit untuk menyerahkan agunan namun persyaratan ini rata-rata kurang dapat dipenuhi nelayan (Nugroho, 2003).

Modal ventura selama ini belum banyak dikenal di bidang kelautan dan perikanan, padahal sektor perikanan tangkap memiliki kendala dalam hal masalah permodalan. Tantangan permodalan ini menjadi masalah klasik sektor perikanan sehingga memerlukan pemecahan yang menyeluruh oleh semua pihak. Keberadaan modal ventura di satu sisi sebenarnya memberikan peluang yang cukup besar untuk menjembatani dan membantu memecahkan masalah tersebut. Namun di sisi lain, sampai saat ini belum ada model yang tepat untuk penggunaan modal ventura dalam perikanan.

Modal Ventura menurut Wardoyo (2003) adalah suatu pembiayaan dalam bentuk penyertaan modal dalam suatu Perusahaan Pasangan Usaha (PPU) yang ingin mengembangkan usahanya untuk jangka waktu tertentu (bersifat sementara). Di dalam pendirian Modal Ventura terdapat dua aspek penting dari maksud dan tujuannya. Pertama, Modal Ventura adalah modal yang disediakan sebagai resiko (Risk Capital) kepada yang mempunyai gagasan (idea), tanpa jaminan pengembalian modal atau keberhasilan di masa mendatang, yang ada hanya sistem bagi hasil berupa dividen. Aspek keberanian pemilik modal menjadi hal penting dalam pengambilan keputusannya. Itu sebabnya dasar utama semangat Modal Ventura terletak pada keyakinan terhadap pasangan usahanya. Kedua, sesuai dengan prinsip dasar yang terkandung dalam "jiwa" Modal Ventura, maka dibuat semacam kesepakatan bahwa penyertaan modal harus bersifat sementara. Jangka waktunya antara 5-10 tahun, sampai mitra usahanya mampu berdiri sendiri barulah sahamnya dijual kembali kepada perusahaan pembiayaan (divestasi). Dalam hal ini penyedia kredit modal ventura cukup melakukan pengawasan, pembinaan dan pembimbingan supaya pelaku usaha perikanan tangkap dapat melakukan manajemen yang baik, tepat dan terarah agar usahanya dapat bertambah maju atau meningkat. Selain itu kredit modal ventura tidak membutuhkan agunan dan pembagian keuntungan sesuai dengan kesepakatan bersama, tidak seperti yang dipersyaratkan oleh bank-bank konvensional.

Studi yang dilakukan oleh Hermawan (2006) menyatakan bahwa sumberdaya perikanan di perairan pantai Kabupaten Tegal telah mengalami tangkap lebih atau overfishing sebesar $40,29 \%$. Hasil penelitian lain yang telah dilakukan oleh Fatchudin (2006) juga menyatakan bahwa subsidi penyaluran kredit perikanan sebaiknya dilakukan melalui mekanisme tipologi dengan melihat ketersediaan sumberdaya ikan dan menerapkan model kredit ke daerah yang masih belum "overfished". Menindaklanjuti hal tersebut, kebijakan dari pemberian kredit 
modal ventura sebaiknya tidak untuk nelayan kecil yang akan menangkap di perairan pantai Kabupaten Tegal namun lebih diarahkan kepada nelayan yang akan berinvestasi ke usaha perikanan tangkap skala besar untuk menjangkau daerah-daerah penangkapan (fishing ground) dimana sumberdaya perikanannya masih under exploited.

Mempelajari dari situasi di atas, pada satu sisi bidang perikanan tangkap menghadapi kendala permodalan dan sisi yang lain ada suatu alternatif baru pembiayaan yaitu dengan kredit modal ventura. Namun tingkat efektifitas pemanfaatan kredit modal ventura belum banyak diketahui, karena belum tersedianya studi-studi modal ventura ini untuk perikanan. Adapun tujuan dari penelitian ini adalah untuk menganalisis efisiensi kredit modal ventura untuk nelayan perikanan tangkap dan sejauh mana kredit modal ventura dapat diinvestasikan oleh nelayan dari penyedia kredit modal ventura.

\section{METODOLOGI}

\section{Jenis dan Teknik Pengumpulan Data}

Data yang dikumpulkan adalah data primer dan data sekunder. Data primer adalah data yang langsung diperoleh dari pengamatan atau pengukuran langsung dari objek penelitian. Pengumpulan data primer dengan cara melakukan wawancara langsung dengan para nelayan perikanan tangkap penerima kredit modal ventura dan sebagai pembanding dengan nelayan perikanan tangkap yang tidak menerima kredit modal ventura dengan aspek-aspek yang relatif sama seperti jenis alat tangkap, jumlah hari melaut dan ukuran kapal. Data primer lainnya adalah pendapatan, biaya operasional, investasi awal, produksi per trip, jumlah Anak Buah Kapal (ABK) per kapal, umur kapal dan pengalaman nelayan.

Data sekunder diperoleh dari Badan Pusat Statistik, Dinas Perikanan, pelabuhan dan tempat pelelangan ikan, koperasi serta instansi-instansi terkait lainnya. Data sekunder antara lain berupa jumlah hasil tangkapan, jumlah armada penangkapan, jumlah dan jenis alat tangkap, jumlah nelayan, peraturan yang mengatur pengelolaan sumberdaya perikanan di pesisir, dan data lainnya yang relevan terhadap tujuan penelitian.

Teknik pengambilan contoh yang digunakan adalah purposive sampling yaitu nelayan yang menerima kredit modal ventura dan nelayan yang tidak menerima kredit modal ventura sebagai pembanding. Pengambilan contoh dilakukan di Kabupaten Tegal pada Bulan Februari sampai Maret 2009.

\section{Metode Analisis Data}

Metode analisis ini merupakan analisis kuantitatif melalui Data Envelopment Analysis (DEA). Menurut Fauzi (2003), DEA atau biasa disebut juga sebagai Frontier Analysis, adalah suatu teknik mathematical programming berupa pendekatan non-parametrik yang dapat digunakan untuk mengukur relatif efisiensi pada kasus di mana entitas yang menjadi variabel pertimbangan memiliki multiple input dan output. Teknik yang dikenal juga sebagai CCR (dari nama depan ketiga orang penemunya: Charnes, Cooper dan Rhodes,1978), merupakan pengukuran terhadap performance efisiensi relatif dari unit pengambil keputusan (decision-making units, DMU) dalam suatu aktivitas. Menurut Beasley (2000), sejak teknik ini diperkenalkan, sudah banyak analisis teoritis dan empiris yang dikembangkan dan diaplikasikan pada perbankan, rumah sakit, perpajakan, sekolah, juga sumberdaya alam, dan lain-lain.

Perumusan DEA dalam penelitian ini dimodifikasi dari formula Fauzi dan Anna (2005) sebagai berikut:

$$
\operatorname{MaxE}_{m}=\frac{\sum w_{i j j m}}{\sum v_{i j k m}}
$$


Dengan kendala:

$$
\begin{aligned}
& \frac{\sum w_{i} y_{i j m}}{\sum v_{k} x_{k j m}} \leq 1 \\
& w_{i}, v_{k} \geq \varepsilon
\end{aligned}
$$

Keterangan:

$$
\begin{aligned}
E_{m}= & \text { Efisiensi kredit perikanan / } \\
& \text { Fishery credit efficiency. } \\
w_{i}= & \text { Bobot untuk output } \mathrm{i} / \\
& \text { Weight of output } \text { I. } \\
v_{k}= & \text { Bobot untuk input } \mathrm{k} / \text { Weight } \\
& \text { of input } \mathrm{k} . \\
y_{j}= & \text { Ouput perikanan (produksi) / } \\
& \text { Fishery output (productions). } \\
x_{k}= & \text { Input (kredit) / Input (credit). }
\end{aligned}
$$

Secara operasional variabel input dalam perikanan terdiri dari tenaga kerja yang digunakan (L), gross tonage (GT), kekuatan mesin (HP), jumlah trip per tahun ( $\mathrm{T})$, dan kredit yang diterima $(\mathrm{K})$, sementara output yang dihasilkan adalah produksi perikanan atau hasil tangkapan (y). Dengan demikian operasionalisasi DEA untuk studi ini ditulis menjadi :

$$
\max E=\frac{\sum_{i=1}^{n} w_{i} y_{i}}{\sum_{i=1}^{n}\left(v_{i l} x_{i l}+v_{i g} x_{i g}+v_{i p} x_{i p}+v_{i t} x_{i t}+v_{i k} x_{i k}\right)}
$$

Keterangan $: i=1 \ldots \ldots . . n$ Jumlah sampel (unit) /Number of sample.

$\operatorname{Dan} \frac{\sum_{i=1}^{n} w_{i} y_{i}}{\sum_{i=1}^{n} v_{i} x_{\lg p t k}} \leq 1$

Dari formula di atas dapat diketahui apakah kredit perikanan selama ini dapat meningkatkan efisiensi perikanan atau tidak. Analisis DEA ini digunakan untuk melihat bagaimana subsidi dalam hal ini kredit akan berpengaruh terhadap efisiensi input output.

\section{HASIL DAN PEMBAHASAN}

Hasil identifikasi kredit modal ventura yang ada atau disalurkan di Kabupaten Tegal ada 7 orang yang bergerak dalam bidang usaha perikanan tangkap. Hasil identifikasi kepada nelayan tangkap penerima kredit modal ventura dapat dilihat pada Tabel 1 . Analisis efisiensi ini dilakukan pada 7 nelayan penerima kredit modal ventura dan 18 nelayan perikanan tangkap lain yang tidak menerima kredit modal ventura, sehingga total nelayan yang menjadi kasus dalam penelitian ini menjadi 25 nelayan perikanan tangkap. Usaha perikanan tangkap dalam analisis ini merupakan kapal-kapal yang melakukan kegiatan penangkapan jauh dari pantai atau dalam 1 trip penangkapan membutuhkan waktu minimal 10 hari melaut. Selanjutnya nelayan yang menjadi kasus atau unit analisis ini akan disebut sebagai Decision Making Unit (DMU).

Nelayan penerima dan bukan penerima kredit modal ventura menggunakan alat tangkap cantrang. Data-data yang digunakan dalam analisis DEA ini antara lain pendapatan per trip dengan 1 trip penangkapan berkisar 10 sampai dengan 26 hari atau rata-rata 21 hari melaut. Biaya operasional penangkapan per trip yang berkisar antara 20 juta rupiah sampai 70 juta rupiah atau rata-rata sekitar Rp. 51.096.000. Investasi awal berkisar antara 80 juta rupiah sampai 600 juta rupiah atau rata-rata sekitar Rp. 393.200.000. Produksi per trip berkisar antara $8.500 \mathrm{~kg}$ sampai $22.375 \mathrm{~kg}$ atau rata-rata sekitar $14.251 \mathrm{~kg}$. Jumlah ABK berkisar antara 12 orang sampai 17 orang atau rata-rata 15 orang per kapal. Umur kapal berkisar antara 3 tahun sampai 11 tahun atau rata-rata sekitar 8 tahun. Pengalaman menjadi nelayan perikanan tangkap berkisar antara 10 tahun sampai 34 tahun atau rata-rata sekitar 23 tahun. Data yang digunakan dalam analisis DEA ini dapat dikelompokkan menjadi dua yaitu input dan output (Tabel1).

Skenario yang dapat dilakukan dalam 
Tabel 1. Mekanisme dan Karakteristik Pengelolaan Kredit Modal Ventura pada Perikanan Tangkap di Kabupaten Tegal, 2009.

Table 1. Mechanism and Characteristic of Ventura Capital Management for the Fishery in Tegal District, 2009.

\begin{tabular}{|c|c|c|c|c|}
\hline No & $\begin{array}{l}\text { Mekanisme Pengelolaan } \\
\text { Kredit Modal Ventura/ } \\
\text { Mechanism of Ventura } \\
\text { Capital Management }\end{array}$ & $\begin{array}{c}\text { Lama Menjadi } \\
\text { Penerima Kredit } \\
\text { (tahun)/ } \\
\text { Time Period Credit } \\
\text { Received } \\
\text { (years) }\end{array}$ & $\begin{array}{l}\text { Besaran } \\
\text { Kredit yang } \\
\text { Diterima } \\
\text { (Rp)/ } \\
\text { Amount of } \\
\text { Credit } \\
\text { Received } \\
\text { (Rp) }\end{array}$ & $\begin{array}{l}\text { Keterangan/ } \\
\text { Note }\end{array}$ \\
\hline 1 & Pendampingan / Assistance & 6 & 900.000 .000 & $\begin{array}{l}\text { diterima dalam } 4 \text { kali } \\
\text { / received in } 4 \text { times }\end{array}$ \\
\hline 2 & Pendampingan / Assistance & 8 & 150.000 .000 & $\begin{array}{l}\text { diterima dalam } 1 \text { kali } \\
\text { / received in } 4 \text { times }\end{array}$ \\
\hline 3 & Pendampingan / Assistance & 1,5 & 75.000 .000 & $\begin{array}{l}\text { diterima dalam } 1 \text { kali } \\
\text { / received in } 4 \text { times }\end{array}$ \\
\hline 4 & Pendampingan / Assistance & 1,5 & 75.000 .000 & $\begin{array}{l}\text { diterima dalam } 1 \text { kali } \\
\text { / received in } 4 \text { times }\end{array}$ \\
\hline 5 & Pendampingan / Assistance & 4 & 450.000 .000 & $\begin{array}{l}\text { diterima dalam } 4 \text { kali } \\
\text { / received in } 4 \text { times }\end{array}$ \\
\hline 6 & Pendampingan / Assistance & 2 & 175.000 .000 & $\begin{array}{l}\text { diterima dalam } 2 \text { kali } \\
\text { / received in } 4 \text { times }\end{array}$ \\
\hline 7 & Pendampingan / Assistance & 3 & 250.000 .000 & $\begin{array}{l}\text { diterima dalam } 3 \text { kali } \\
\text { / received in } 4 \text { times }\end{array}$ \\
\hline
\end{tabular}

analisis DEA adalah maximizing output atau minimizing input. Data yang menjadi output dalam pengolahan analisis DEA adalah pendapatan per trip dan produksi per trip, sedangkan yang menjadi input adalah biaya operasional per trip, investasi awal, jumlah ABK, umur kapal penangkap ikan dan pengalaman menjadi nelayan perikanan tangkap. Pada pengolahan analisis DEA ini dapat dilakukan kedua skenario di atas dengan menggunakan seluruh data baik input maupun output. Namun agar skenario di atas dapat menggambarkan frontier analysis maka syarat yang diharuskan adalah : (1) pada maximizing output menggunakan: 1 output 2 input, atau, (2) pada minimizing input menggunakan: 2 output 1 input. Selengkapnya data-data yang digunakan dalam analisis DEA ini dapat dilihat pada Lampiran 1.
Analisis DEA yang pertama kali dilakukan adalah dengan menggunakan semua data input dan output dari tabel di atas, dimana data input adalah biaya operasional, investasi awal, jumlah ABK, umur kapal dan pengalaman menjadi nelayan sedangkan data output adalah pendapatan dan produksi per trip. Hasil analisis DEA dengan menggunakan semua input dan output ini menunjukkan bahwa dari 7 nelayan yang menerima kredit modal ventura ada 6 nelayan yang mempunyai skor $100 \%$ atau efisien dalam melakukan usaha perikanan tangkap (DMU : 7, 5, 3, 1, 6, 2) dan hanya 1 nelayan yang belum efisien mempunyai skor 98,32\% (DMU : 4 mendekati $100 \%)$. Nelayan penerima kredit modal ventura yang belum efisien ini (DMU : 4) dinilai wajar karena baru menjadi penerima kredit modal ventura selama 1,5 tahun. Pada nelayan yang tidak menerima bantuan kredit 




Gambar 1. Plot Analisis Frontier Nelayan Perikanan Tangkap dengan Memasukkan Semua Input dan Output di Kabupaten Tegal, 2009.

Figure 1. Frontier Analysis Plot of Tegal Fishers Household with All Inputs and Outputs Data in Tegal District, 2009.

modal ventura yang sudah efisien atau skor sudah mencapai $100 \%$ ada 2 nelayan (DMU : 14 dan 23), sedangkan 16 nelayan perikanan tangkap lainnya masih belum efisien dimana skor berkisar antara 70-96\% (DMU : 9, 16, 15, $24,13,21,12,11,8,20,25,18,22,10,19,17)$. Pada analisis DEA dengan menggunakan semua data baik dari input maupun dari output menunjukkan kredit modal ventura akan menggiring nelayan penerima kredit modal ventura menjadi efisien / efektif dalam usaha perikanan tangkap.

Untuk melihat sejauh mana posisi nelayan yang tidak efisien dengan nelayan yang efisien, maka dilakukan analisis efficiency plot yang menggambarkan letak efisiensi dari masing-masing nelayan DMU. Hasil analisis efficiency plot menunjukkan bahwa DMU : 3, 14, 6, 7, 23 dan 5 berada pada garis frontier efisien (berhimpitan pada garis merah terluar) dan DMU : 17 berada jauh dari garis efficiency plot yang menunjukan DMU yang paling tidak efisien. Efisiensi plot nelayan penerima kredit modal ventura dan nelayan yang tidak menerima kredit modal ventura dengan memasukkan semua input dan output dapat dilihat pada Gambar 1.

Analisis DEA memungkinkan mencari potensi perbaikan atas unit-unit DMU yang tidak efisien. Artinya jika satu unit DMU tidak efisien kira-kira berapa komponen input dan output yang bisa ditambah atau dikurangi (dalam persen) untuk mencapai target level input dan output yang efisien.

Hasil analisis potential improvement menunjukkan bahwa output dari sisi pendapatan perlu ada peningkatan sebesar $3,39 \%$ dan dari sisi produksi per trip perlu ada 
peningkatan sebesar 2,07\%. Dari diagram pie pada Gambar 2 tampak bahwa biaya operasional per trip, investasi awal, jumlah ABK, pengalaman dan umur kapal harus diturunkan agar dapat mencapai efisien yang ditunjukkan oleh tanda negatif pada legenda di Gambar 2. Penurunan masing-masing yaitu $15,33 \%, 16,02 \%, 14,85 \%, 14,65 \%$ dan $33,69 \%$. Secara total, potential improvement untuk input dan output dapat dilihat pada Gambar 1. perikanan tangkap di Kabupaten Tegal baik penerima kredit modal ventura maupun yang bukan, mempunyai efektifitas atau efisiensi yang cukup baik (semuanya berada $>70 \%$ ). Hal ini menunjukkan bahwa usaha perikanan tangkap skala besar masih memberikan peluang dan dampak yang baik bagi para nelayan untuk mencari daerah fishing ground dimana pemanfaatan sumberdaya perikanannya masih rendah (under exploited). Seperti dijelaskan sebelumnya agar skenario

\section{Total Potential Improvement}

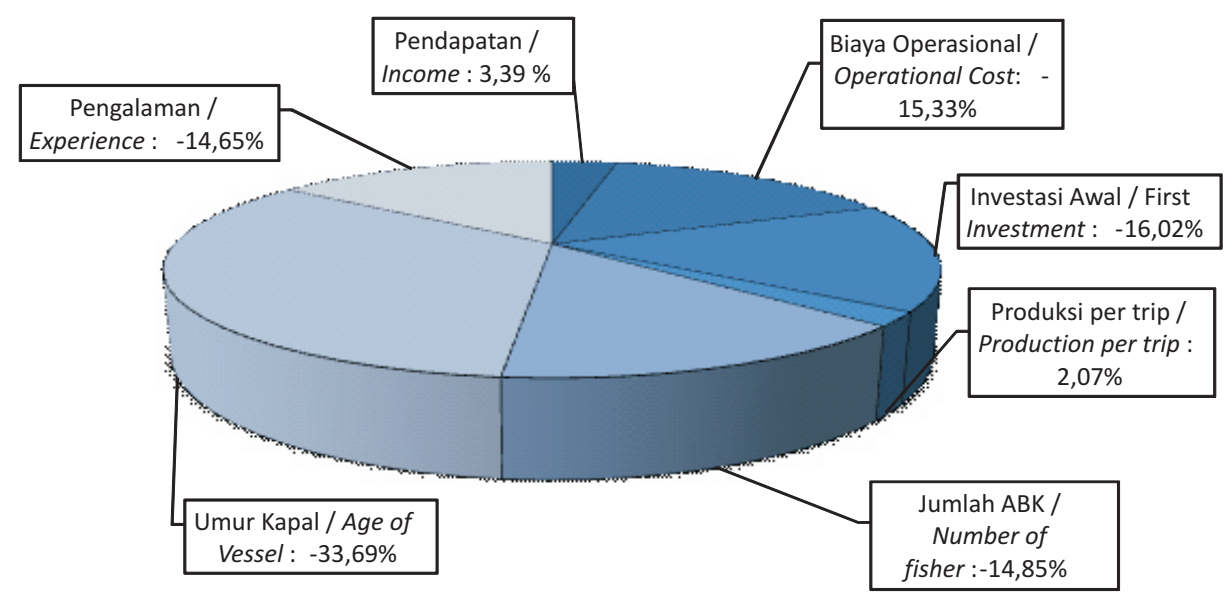

\section{Gambar 2. Diagram Pie Total Potential Improvement dengan Memasukkan Input dan Output dalam Analisis DEA, Kabupaten Tegal, 2009.}

Figure 2. Pie Diagram of Total Potential Improvement By Using All Input and Output Data in the DEAAnalysis, Tegal District, 2009.

Untuk melihat distribusi skor DMU dalam kurva sebaran normal dapat dilihat pada Gambar 3. Pada Gambar 3 dapat dilihat bahwa distribusi skor berada di atas $70 \%$, dimana ada 5 DMU berada skor $71-80 \%, 6$ DMU berada pada skor 81-90\%, 6 DMU berada pada skor $91-99,9 \%$ dan sisanya 8 DMU yang paling efisien atau berada pada skor $100 \%$. Jika melihat distribusi DMU dalam kurva sebaran normal terlihat bahwa nelayan analisis DEA dapat menggambarkan frontier analysis maka syarat yang diharuskan adalah : 1) pada maximizing output menggunakan :1 output 2 input atau

2) pada minimizing input menggunakan : 2 output 1 input.

Oleh karena itu, dalam analisis DEA pada maximizing output akan digunakan 1 output yaitu produksi per trip dan 2 input yaitu biaya operasional dan umur kapal. Alasan penggunaan produksi adalah untuk 


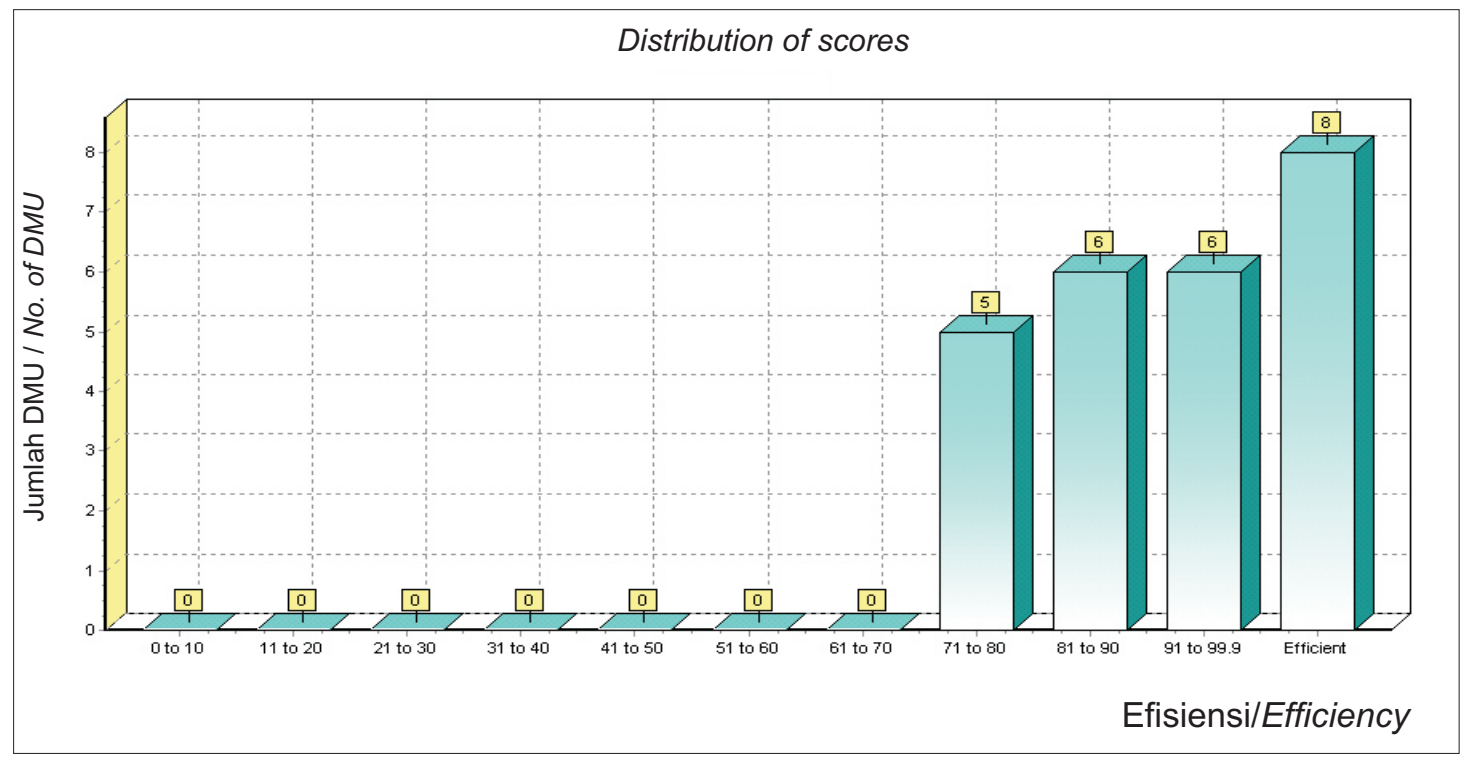

Gambar 3. Distribusi Skor dari DMU Penerima dan Bukan Penerima Kredit Modal Ventura di Kabupaten Tegal, 2009

Figure 3. Score Distribution of DMU Who Received and Non Received Ventura Credit Capital in Tegal District, 2009.

menggambarkan kondisi sumberdaya perikanan yang diambil, sedangkan biaya operasional dan umur kapal dari sisi penggunaan kapital atau modal dalam usaha perikanan tangkap. Pada minimizing input akan digunakan 2 output yaitu pendapatan dan produksi serta inputnya adalah biaya operasional per trip. Selengkapnya skenario analisis DEA agar dapat menggambarkan frontier analysis dapat dilihat pada Tabel 2.

Tabel 2. Input dan Output yang Digunakan pada Skenario Maksimisasi Output dan Minimisasi Input Perikanan Tangkap di Kabupaten Tegal, 2009.

Table 2. Input and Output Used in the Scenario of Maximizing Output and Minimizing Input of Fishing in Tegal District, 2009.

\begin{tabular}{|c|c|c|c|c|c|c|}
\hline \multirow{2}{*}{$\begin{array}{l}\text { Skenario/ } \\
\text { Scenario }\end{array}$} & \multicolumn{3}{|c|}{$\begin{array}{c}\text { Maksimisasi Output/ } \\
\text { Maximizing Output }\end{array}$} & \multicolumn{3}{|c|}{$\begin{array}{l}\text { Minimisasi Input/ } \\
\text { Minimizing Input }\end{array}$} \\
\hline & Output & Input 1 & Input 2 & Output 1 & Output 2 & Input \\
\hline 1 & $\begin{array}{l}\text { Produksi/ } \\
\text { Production }\end{array}$ & $\begin{array}{c}\text { Biaya } \\
\text { Operasional } \\
\text { per trip/ } \\
\text { Operational } \\
\text { Cost per Trip }\end{array}$ & $\begin{array}{l}\text { Umur } \\
\text { Kapal/ } \\
\text { Age of } \\
\text { Vessel }\end{array}$ & & & \\
\hline 2 & & & & $\begin{array}{l}\text { Pendapatan } \\
\text { per Trip/ } \\
\text { Income per } \\
\text { Trip }\end{array}$ & $\begin{array}{l}\text { Produksi } \\
\text { per Trip/ } \\
\text { Production } \\
\text { per Trip }\end{array}$ & $\begin{array}{c}\text { Biaya } \\
\text { Operasional } \\
\text { per Trip / } \\
\text { Operational } \\
\text { Cost per } \\
\text { Trip }\end{array}$ \\
\hline
\end{tabular}




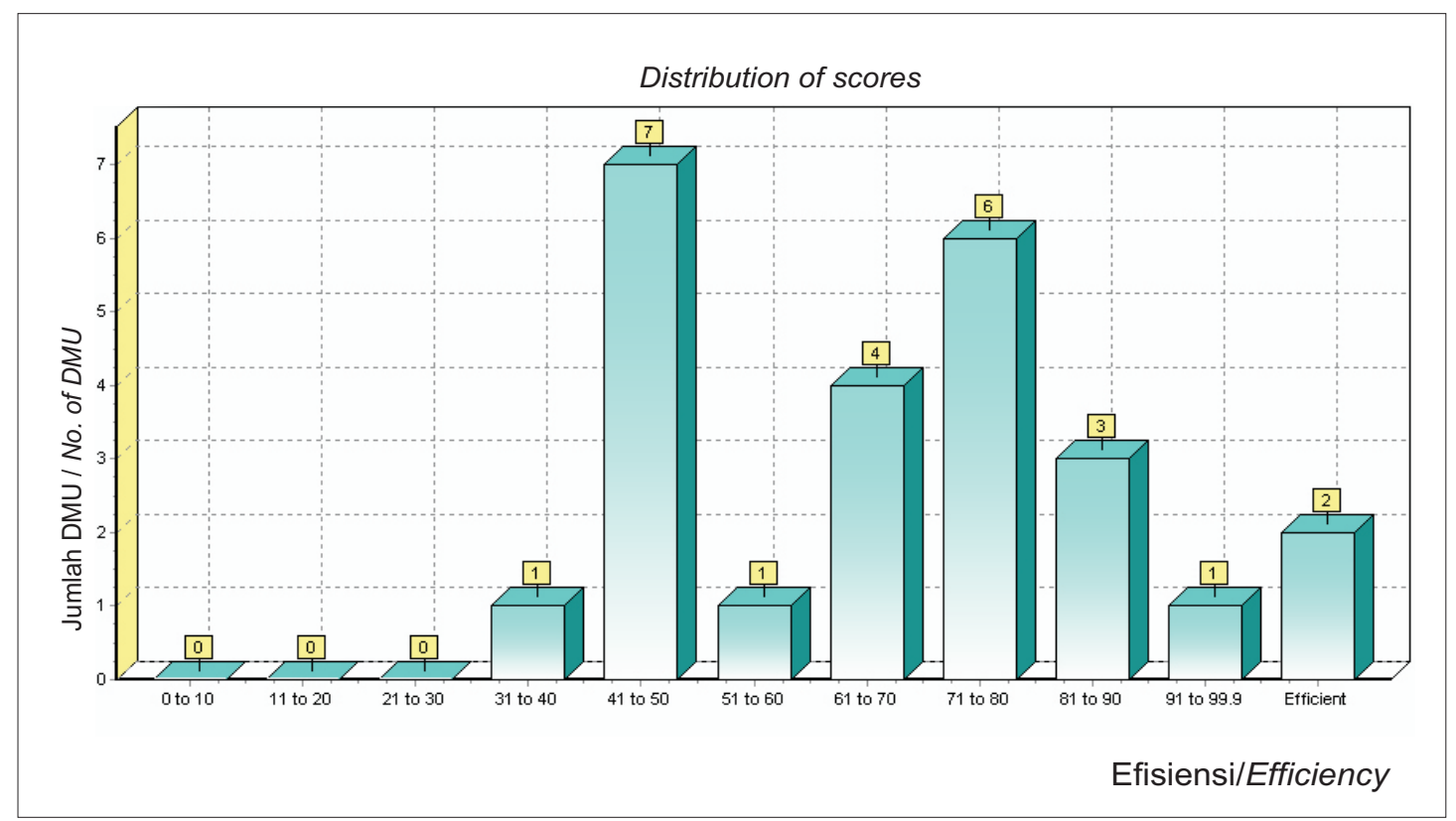

Gambar 4 Distribusi Skor dari DMU dengan Skenario 1 di Kabupaten Tegal, 2009.

Figure 4. Score Distribution of DMU with First Scenario in Tegal District, 2009.

Skenario 1 : Maximizing Output (Produksi) dengan Mempertimbangkan Variabel Input Biaya Operasional Per Trip dan Umur Kapal pada Perikanan Tangkap di Kabupaten Tegal.

Analisis dengan menggunakan skenario 1 menunjukkan nelayan yang efisien mencapai $100 \%$ terdiri dari 2 DMU yaitu DMU: 3 dan 2. Nelayan yang paling tidak efisien adalah DMU: 8 sebesar 39,50\%. Pada skenario 1 ini terjadi penurunan DMU yang efisien dari 6 DMU menjadi 2 DMU dan terjadi penurunan komposisi skor jauh lebih rendah dimana 12 DMU yang menjadi kurang dari $70 \%$. Nelayan penerima kredit modal ventura tingkat efisiensinya masih di atas $70 \%$ tapi dibawah $100 \%$ ada 11 DMU yaitu DMU : 5, 7, 4, dan 6 kecuali DMU: 1 yang turun drastis dari $100 \%$ menjadi kurang dari $50 \%$. Kasus pada DMU: 1 ini terjadi karena produksi perikanan yang dihasilkan tidak sebanding dengan biaya operasional yang digunakan. Jika dilihat dari komposisi sebaran skor antara nelayan penerima kredit modal ventura dan yang tidak menerima, tingkat efisien dihasilkan lebih tinggi pada nelayan yang menerima kredit modal ventura. Selengkapnya hasil analisis DEA dan distribusi skor dari penerima kredit dan yang tidak menerima kredit dengan Skenario 1 dapat dilihat pada Gambar 4.

Hasil analisis total potential improvement menunjukkan bahwa output dari sisi produksi perlu ada peningkatan relatif antar DMU sebesar $96,23 \%$. Nilai peningkatan ini sangat tinggi sekali yang menunjukkan bahwa tingkat produksi pada maximizing output sangat berpengaruh sensitif terhadap efisiensi usaha perikanan tangkap. Dari diagram pie pada Gambar 5 tampak bahwa biaya operasional per trip harus diturunkan sebesar $1,69 \%$ dan umur kapal harus diturunkan atau diremajakan sebesar 2,07\% agar dapat mencapai efisien yang ditunjukkan oleh tanda negatif pada legenda di Gambar 5. Secara total, potential improvement untuk input dan output dapat dilihat pada Gambar 5. 




\section{Gambar 5. Diagram Pie Total Potential Improvement Skenario 1 pada Perikanan Tangkap di Kabupaten Tegal, 2009.}

Figure 5. Pie Diagram of Total Potential Improvement with First Scenario of Fishing in Tegal District, 2009.

Gambar 6 menunjukkan posisi masingmasing DMU dalam garis frontier. Garis frontier adalah garis merah yang membentuk siku (L-shaped) pada sudut titik nol, sementara garis biru adalah garis referensi efisiensi. Hasil analisis frontier pada skenario 1 : maximizing output menunjukkan bahwa DMU : 3 dan 2 berada pada garis frontier efisien (berhimpitan pada garis merah), diikuti oleh DMU : 5 yang paling mendekati garis merah. DMU : 8 berada jauh dari garis frontier yang menunjukkan DMU yang paling tidak efisien. Garis referensi (warna biru) menunjukkan bahwa untuk mengarah ke efisiensi ditunjukkan pada garis yang mengarah ke aksis horizontal-vertikal. Artinya, DMU 1 misalnya bisa ditingkatkan efisiensinyai jika rasio biaya operasional/produksi per trip dikurangi. Artinya tanpa menambah kredit, dengan mengurangi komponen biaya yang tidak efisien, maka DMU 1 bisa lebih efisien dan akan mengikuti DMU 3 dan 2 pada posisi efisiensi.
Salah satu contoh dari Gambar 6 juga terlihat bahwa posisi "peer" dari DMU : 4, 6, dan 14 adalah DMU : 3, artinya jika DMU : 4, 6, dan 14 tersebut ingin efisien, maka referensi yang terdekat adalah melihat keragaan yang dilakukan oleh DMU : 3. DMU 8 di sisi lain posisinya jauh dari "peer" manapun sehingga sulit meningkat efisiensi tanpa mengurangi secara drastis total komponen biaya operasional dan peningkatan produksi per tripnya.

Skenario 2 : Minimizing Input (biaya operasional per trip) dengan Mempertimbangkan Output Pendapatan dan Produksi Perikanan Tangkap di Kabupaten Tegal, 2009

Pada skenario 2, analisis menunjukkan nelayan yang efisien mencapai $100 \%$ juga terdiri dari 2 DMU yaitu DMU : 3 dan 5, dimana DMU : 3 tetap efisien namun DMU : 2 bergeser menjadi 90,88\% digantikan oleh DMU : 5 . Nelayan yang paling tidak efisien tetap DMU : 8 sebesar $54,25 \%$. Pada skenario 2 ini juga terjadi penurunan DMU yang efisien dari 6 


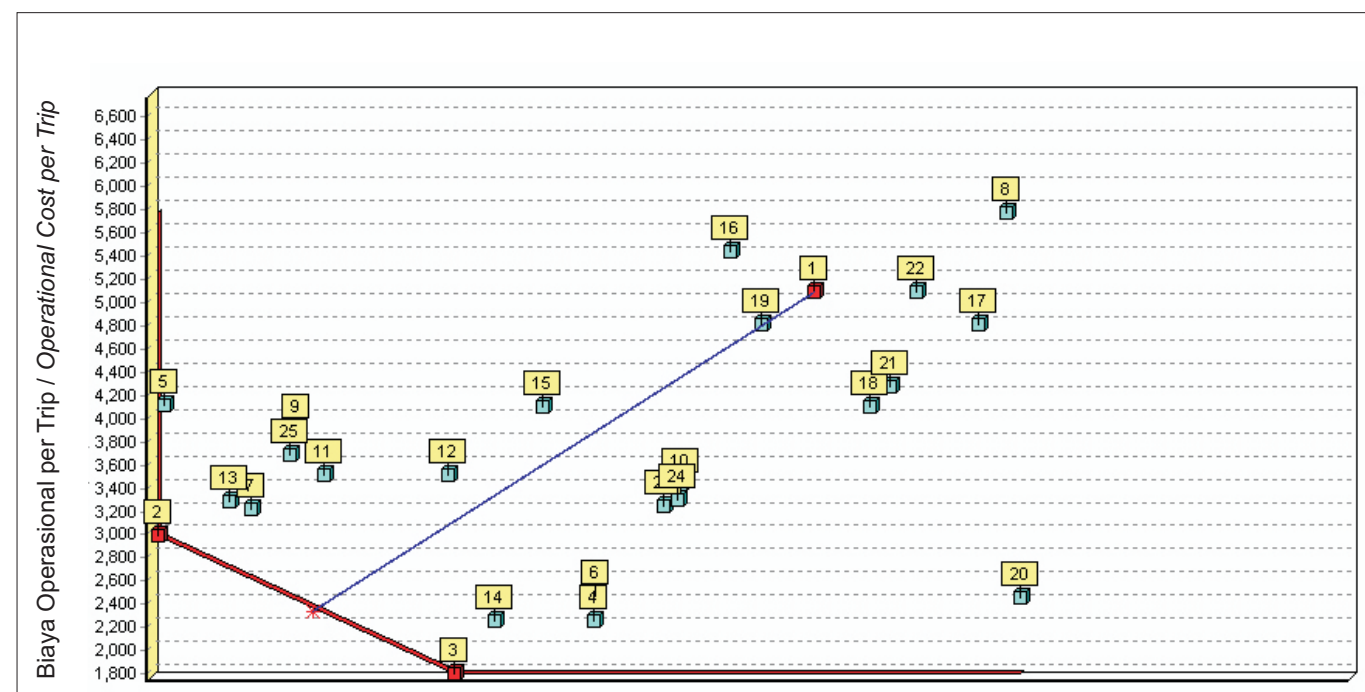

Umur Kapal per Trip / Age of Vessel per Trip

\section{Gambar 6. Plot Analisis Frontier dengan Skenario 1 pada Perikanan Tangkap di Kabupaten Tegal, 2009.}

Figure 6. $\quad$ Frontier Analysis Plot of Tegal Fishers Household with First Scenario of Fishing in Tegal District, 2009.

DMU menjadi 2 DMU dibandingkan saat semua data input dan output digunakan dalam analisis DEA. Penurunan komposisi skor juga terjadi dimana 8 DMU yang menjadi kurang dari $70 \%$. Nelayan penerima kredit modal ventura tingkat efisiensinya masih di atas $70 \%$ tapi dibawah $100 \%$ ada 15 DMU yaitu DMU : $17,7,18,13,25,20,24,15,4,6,1,9,2,14$ dan 23. Jika dilihat dari komposisi sebaran skor antara nelayan penerima kredit modal ventura dan yang tidak menerima, tingkat efisien dihasilkan tetap lebih tinggi pada nelayan yang menerima kredit modal ventura baik pada skenario 1 , skenario 2 maupun pada saat semua data input dan output digunakan dalam analisis DEA. Selengkapnya hasil analisis DEA dan distribusi skor dari penerima kredit dan yang tidak menerima kredit dengan Skenario No. 2 dapat dilihat pada Gambar 7 .

Dari diagram pie pada Gambar 8 tampak bahwa biaya operasional per trip harus diturunkan relatif antar DMU sebesar 97,26\% agar dapat mencapai efisien yang ditunjukkan oleh tanda negatif pada legenda di Gambar 8. Nilai penurunan ini sangat tinggi sekali yang menunjukkan bahwa biaya operasional per trip pada minimizing input sangat berpengaruh sensitif terhadap efisiensi usaha perikanan tangkap. Hasil analisis total potential improvement menunjukkan bahwa output dari sisi pendapatan sudah tidak perlu ditingkatkan, namun dari sisi produksi per trip perlu ada peningkatan sebesar 2,24\%. Secara total, potential improvement untuk input dan output dapat dilihat pada Gambar 8. Dari Gambar frontier analysis dibawah kita dapat melihat sejauh mana posisi nelayan penerima kredit modal ventura dengan nelayan yang tidak menerima kredit modal ventura. Analisis frontier yang menggambarkan posisi kedekatan (peer position) satu DMU dengan DMU lainnya. Gambar 9 menunjukkan posisi masing-masing DMU dalam garis frontier. Garis frontier adalah garis tebal yang menunjukkan garis efisien DMU, sementara garis biru adalah garis 


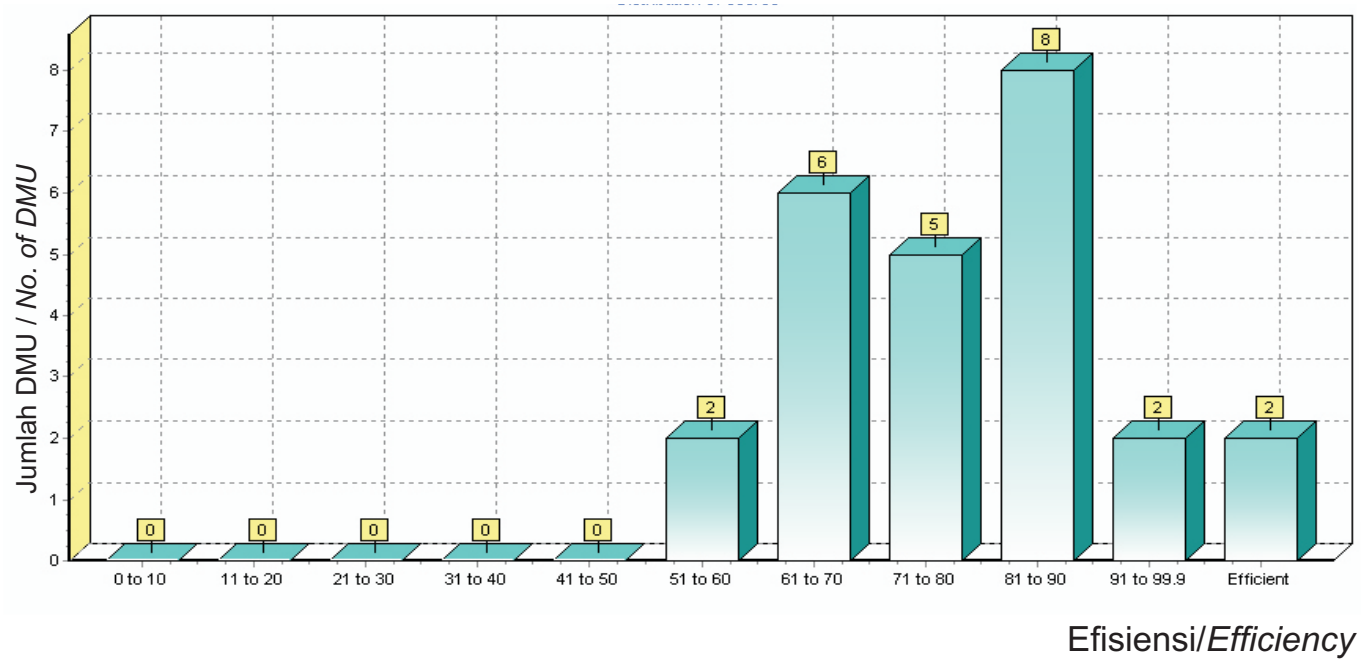

Gambar 7. Distribusi Skor dari DMU dengan Skenario 2 pada Perikanan Tangkap di Kabupaten Tegal, 2009.

Figure 7. Score Distribution of DMU Tegal Fishers Household with Second Scenario of Fishing in Tegal District, 2009.

referensi efisiensi. Hasil analisis frontier pada skenario 2 : minimizing input menunjukkan bahwa DMU : 3 dan 5 berada pada garis frontier efisien (berhimpitan pada garis merah), diikuti oleh DMU : 23 yang paling mendekati garis merah. DMU : 8 berada jauh dari garis frontier yang menunjukan DMU yang paling tidak efisien. Garis referensi (warna biru) menunjukkan bahwa untuk mengarah ke efisiensi (garis merah) ditunjukkan oleh garis yang mengarah dari aksis horizontal-vertikal. Artinya, DMU 1 misalnya bisa ditingkatkan

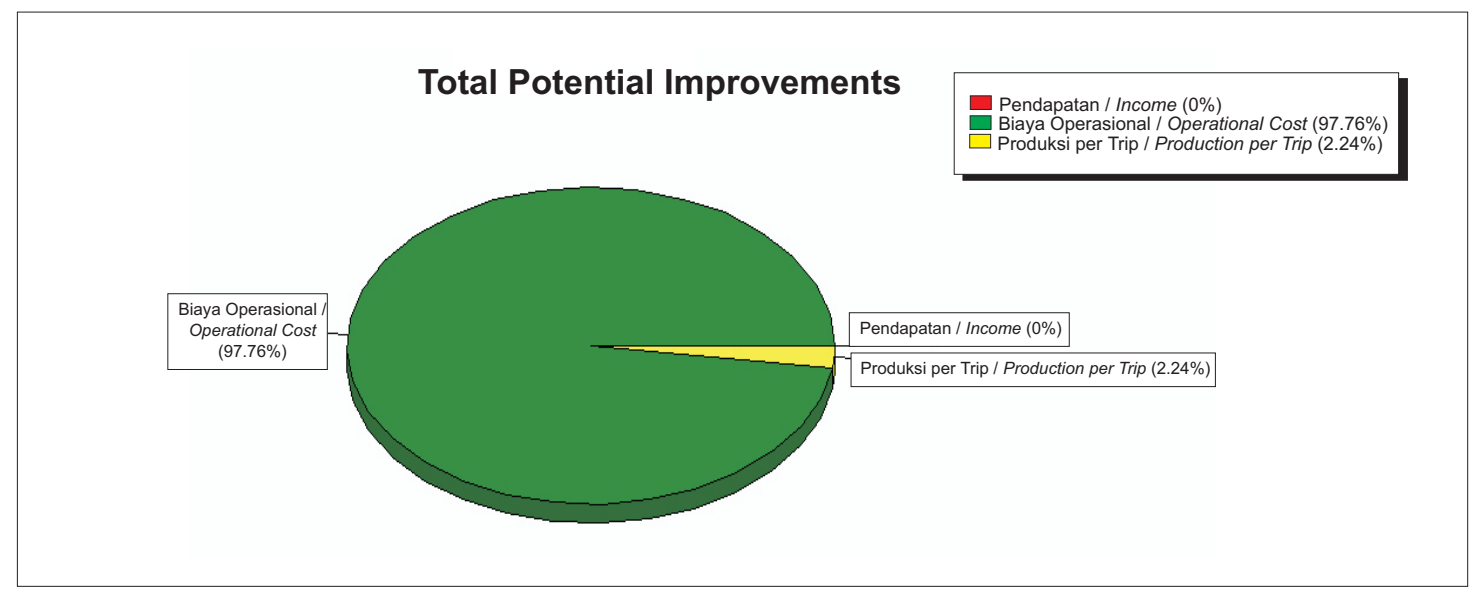

Gambar 8. Diagram Pie Total Potential Improvement Skenario 2 pada Perikanan Tangkap di Kabupaten Tegal, 2009.

Figure 8. Pie Diagram of Total Potential Improvement Tegal Fisher's Household with Second Scenario of Fishing in Tegal District, 2009. 




Gambar 9. Plot Analisis Frontier pada Perikanan Tangkap di Kabupaten Tegal dengan Scenario 2.

Figure 9. Frontier Analysis Plot of Tegal Fishers Household with Second Scenario of Fishing in Tegal District, 2009.

efisiensi jika rasio produksi/biaya operasional per trip ditingkatkan. Artinya tanpa menambah kredit, dengan meningkatkan produksi, maka DMU 1 bisa lebih efisien dan akan mengikuti DMU 3 dan 5 pada posisi efisiensi.

Salah satu contoh dari Gambar 9 juga terlihat bahwa posisi "peer" dari DMU : 4, 6, 14 dan 20 adalah DMU: 3 , artinya jika DMU: 4, 6 , 14 dan 20 tersebut ingin efisien, maka referensi yang terdekat adalah melihat keragaan yang dilakukan oleh DMU: 3 . DMU 8 di sisi lain posisinya jauh dari "peer" manapun sehingga sulit meningkat efisiensi tanpa mengurangi secara drastis total komponen biaya operasional dan peningkatan produksi pertripnya.

\section{KESIMPULAN DAN IMPLIKASI KEBIJAKAN}

Kesimpulan yang dapat diperoleh dari hasil penelitian ini adalah :

1) Multiple input output (semua data input output dimasukkan) ada 8 DMU yang efisiensinya mencapai $100 \%$, yaitu DMU :
7, 5, 3, 1, 6, 2, 14 dan 23. Hal ini menunjukkan dari 7 nelayan yang menerima kredit modal ventura ada 6 yang telah mencapai efisien $100 \%$, artinya kredit modal ventura ini memberikan dampak positif pada usaha perikanan tangkap di Kabupaten Tegal.

2) Skenario 1, ada 2 DMU yang efisiensinya mencapai $100 \%$ yaitu DMU: 3 dan 2, dimana keduanya adalah penerima kredit modal ventura. Ke-4 DMU penerima kredit modal ventura lainnya berada > 70\% yaitu DMU: 5, 7, 4, 6 dan 1 DMU yang berada < 70\% yaitu DMU: 1 . DMU 1 mempunyai efisiensi $<70 \%$ karena produksi perikanan yang dihasilkan tidak sebanding dengan biaya operasional yang digunakan.

3) Skenario 2, ada $2 \mathrm{DMU}$ yang efisiensinya mencapai $100 \%$ yaitu DMU : 3 dan 5 , dimana keduanya adalah penerima kredit modal ventura. Ke-5 DMU penerima kredit modal ventura lainnya berada > $70 \%$ yaitu DMU : 2, 1, 6, 4 dan 7 . 
4) Secara umum kredit modal ventura memberikan pengaruh positif pada usaha perikanan tangkap di Kabupaten Tegal.

Implikasi kebijakan yang dapat diberikan dari hasil penelitian ini adalah :

1. Pada analisis potential improvement dan analisis frontier pada DEA, pemberian kredit ventura harus memperhatikan aspek-aspek atau potensi-potensi perbaikan dari keragaan/kapasitas perikanan seperti pengalaman menjadi nelayan, jumlah $\mathrm{ABK}$, hari melaut, umur kapal dan peningkatan produksi agar dapat diperoleh tingkat efisiensi yang optimal dalam pengembalian kredit ventura yang diberikan.

2. Kebijakan perkreditan perikanan memang harus di kembangkan namun diperlukan "new strategy" yang lebih tegas tentang pemberian kredit. "new strategy" ini dapat dijabarkan baik dalam bentuk "blue print" strategi perkreditan perikanan maupun peraturan pemerintah yang harus mengakomodasi keunikan karakteristik usaha perikanan.

3. Pada tingkat mikro operasional, penyaluran kredit perikanan sebaiknya dilakukan melalui mekanisme tipologi dengan melihat ketersediaan sumberdaya ikan, keragaan usaha perikanan dan besaran kredit yang akan disalurkan.

4. Model dalam studi ini diterapkan pada kasus perikanan yang sebenarnya sudah diklaim sebagai daerah "overfished". Untuk menerapkan model kredit ini ke daerah yang masih belum "overfished" diarahkan kepada analisis komoditas ekonomis penting dari sumberdaya ikan yang dapat diberikan kredit perikanan sehingga terjadi efisiensi kredit perikanan berupa kredit modal ventura dalam peningkatan produksi perikanan.

\section{DAFTAR PUSTAKA}

Beasley, J.E. 2000. Data Envelopment Analysis. Notes.http://mscmga.ms.ic.ac. uk/ jeb.14pp.

Charnes. A., Cooper W.W, and E.Rhodes. 1978. Measuring the Efficiency of Decision Making Units. European Journal of Operation Research 2 : 429-444

Fatchudin. 2006. Analisis Kebijakan Perkreditan Untuk Pengelolaan Perikanan Tangkap yang Berkelanjutan. Disertasi. Sekolah Pascasarjana Institut Pertanian Bogor., Bogor.

Fauzi, A. 2003. Bahan Kuliah Ekonomi Pembangunan Perikanan. Program Pasca Sarjana IPB., Bogor.

Fauzi, A dan S. Anna. 2005. Pemodelan Sumber Daya Perikanan dan Kelautan untuk Analisis Kebijakan. PT Gramedia Pustaka Utama., Jakarta.

Hermawan, M. 2006. Keberlanjutan Perikanan Tangkap Skala Kecil. Disertasi. Sekolah Pascasarjana Institut Pertanian Bogor., Bogor.

Nugroho, U. 2003. Mengkaji Pemberian Kredit SektorKelautan. Kompas, 23 Juli 2003. Wardoyo. 2003. Modal Ventura Salah Satu Alternatif Pembiayaan. Harian Republika, 23 Oktober 2003.

\section{UCAPAN TERIMA KASIH}

Penulis mengucapkan banyak terima kasih kepada (alm). Bapak Ach. Nafani Manaf, yang telah melibatkan penulis dalam proses pencarian data dan penelitian. 